\title{
COSTOS DE IMPORTACIÓN
}

\section{CPC. JORGE GAVELÁN IZAGUIRRE}

\section{NATURALEZA DEL COSTO DE IMPORTACIÓN}

El costo de importación está constituido por el precio original de compra, más todos los gastos incurridos para poner el producto importado en el almacén de la empresa. Estos gastos adicionales están constituido por: flete, seguro, derechos e impuestos que gravan la importación, transporte, acarreo y gastos de aduana en general; por consiguiente incluye todos los gastos atribuibles directamente al producto, así como también los indirectos, como son los gastos administrativos generados por los entes que apoyan a la operación de compra-venta del exterior. No se incluye en el costo de importación a los gastos financieros, por ser ajenos al valor real de la mercancía importada.

Para determinar el momento de registro de los documentos es imprescindible precisar el instante en que el comprador (importador) adquiere legalmente la condición de propietario, lo que se hace a través de términos e indicaciones utilizados en el comercio internacional mencionados en la carta de crédito, facturas y demás documentos complementarios. Así por ejemplo, la adquisición puede ser a valor FOB (Free on Board, traducido como Libre a Bordo). En este caso, se asume la propiedad desde el momento en que es dejada la mercancía en el puerto de embarque. En el método C \& F (Cost and Freight, traducido como costo y flete), el derecho de propiedad se origina cuando llega la mercancía al puerto de desembarque.

No es posible establecer por los procedimientos contables convencionales, el registro de los documentos referidos a la importación, ni tampoco determinar el costo total de adquisición. Es necesario modificar algunas prácticas de registración contable y de control e inclusocrear registros de apoyo contable, que permitan determinar correcta y oportunamente el costo de importación.

En la actividad de importación participan dos clases de monedas: la de uso corriente del país importador y la del exportador, pudiendo los contratantes convenir en utilizar una tercera considerada "moneda fuerte". En los libros contables del importador se registra los documentos en moneda extranjera por su equivalente en la moneda de curso legal, cuya suma ha de ser diferente a la que corresponde a la del momento de pago de la obligación, por efecto de la variación en la cotización de la moneda extranjera en el tiempo, lo que requiere un tratamiento contable adicional de regularización, teniendo usualmente por efecto el incremento del costo de importación.

\section{LIQUIDACIÓN DE LOS IMPUESTOS Y DERECHOS DE IMPORTACIÓN}

Cuando las mercancías han llegado al puerto de destino y el porteador marítimo (o representante del medio de transporte) entrega la mercancía y los documentos de despacho al banco del país importador, y éste comunica o confirma al importador que la mercancía se encuentra a su disposición, previo pago o cumplimiento de las condiciones previstas en la carta de crédito, el importador o su representante (agente de aduana), procede a efectuar las gestiones del caso ante la SUNAD para internar la mercancía al país y solicitar su posterior despacho a consumo (retiro de la aduana). 
Previa liquidación y cancelación de los derechos e impuestos en los plazos señalados, la mercancía es retirada de la aduana y recepcionada en el almacén de la empresa.

Los documentos referidos a la liquidación de impuestos son la DUI (Declaración Única de Importación) y la factura del agente de aduana, siendo el segundo una réplica resumida del primero. Al precisar las características principales de estos documentos se tiene:

\section{DUI (Declaración única de importación)}

Es un documento establecido por la SUNAD, en el cual se liquida (por el agente de aduana) en dólares americanos, impuestos y derechos por cada artículo importado sobre la base del valor CIF, luego convertido a moneda nacional se aplica el TCV del día. Se toma como punto de partida la factura del proveedor, y en caso extremo el valor establecido por la empresa supervisora de importaciones, la que tiene por función obtener la base correcta de liquidación de los impuestos aduaneros, además de verificar la cantidad, calidad, precio, condición y partida arancelaria de las mercancías.

La empresa supervisora emite en el puerto de origen, el certificado de inspección establecido en la vigente Ley General de Aduana (D.L. 809 del 19-04-96).

Los principales impuestos que gravan la importación son los siguientes:

-Impuesto Ad-Valorem.- Se aplica la tasa según partida arancelaria, que se calcula sobre el valor CIF aduanero (FOB + flete + seguro) del artículo importado, así hubiera sido otra la condición de compra (FOB, C\&F, FAS, etc.). El D.S. No 119-97-EF publicado el 29-09-97 Arancel de Aduanas estableció las tasas de $12 \%$ ó $20 \%$.
-Sobretasa.- Grava a algunos productos agropecuarios con la tasa de $5 \%$ que se aplica sobre la base del valor CIF.

-Impuesto general a las ventas.- Se calcula sobre la suma del valor CIF aduanero y el derecho Ad-Valorem con la tasa de 16\%. Asimismo, si el producto importado está además gravado con el Impuesto Selectivo al Consumo (ISC), este último forma parte de la base imponible para el cálculo del IGV.

-Impuesto de promoción municipal.- Se calcula sobre la suma del valor CIF aduanero y el derecho Ad-Valorem. La tasa que se aplica es del $2 \%$.

-Impuesto selectivo al consumo.La base imponible está constituida por el valor CIF aduanero y el monto de los derechos Ad-Valorem que grava la mercancía especificada en los apéndices III y IV. de la Ley del IGV. e ISC, con tasas que en promedio fluctúan entre $10 \%$ y $45 \%$.

-Derechos específicos.-Grava a determinados productos alimenticios e insumos agropecuarios como: leche, arroz, trigo, azúcar, maíz, etc. Se aplica un valor en US $\$$ por tonelada métrica, según tablas aduaneras.

-Derechos antidumping y derechos compensatorios.- Son multas cuya finalidad es anular el efecto negativo de mercancías ingresadas al país a precios de dumping 0 subvencionadas que dañan o amenazan a la producción nacional. Ambos derechos se calculan sobre el valor FOB de la mercancía, de acuerdo al reglamento sobre Dumping y Subvenciones D.S. No 049-97-EF.

\section{Factura del agente de aduana}

Este documento es de forma diferente al establecido por el Reglamento de Com- 
probantes de Pago, el que se divide en dos partes principales:

Primera parte.- Indica los tributos pagados en el banco que deben ser una transcripción exacta de las sumas indicadas en la DUI. El importe del impuesto Ad-Valorem forma parte del costo de importación y el IGV e IPM forman parte del crédito tributario a anotar en el Registro de Compras.

Segunda parte.- Indica los gastos que ha efectuado el agente de aduana en los trámites de retiro de la mercancía del terminal marítimo o aéreo, los que en lo posible deben estar sustentados documentariamente a efectos de tener la certeza que la suma a reembolsar es real o razonable, éstos son: movilidad, fotocopias, carguío, trámite documentario, etc.
Además se incluye la comisión del agente de aduana por sus servicios, el que se calcula sobre el total de la suma liquidada y pagada en la importación (impuestos más gastos pagados por el agente), aplicando un porcentaje previamente pactado, el que fluctúa entre $3 \%$ y $5 \%$. Además sobre la comisión se calcula el IGV, al estar afecto la prestación del servicio. El cálculo de los impuestos y derechos de importación, se precisa a continuación en el siguiente ejemplo:

Quiruvilca S.A. ha importado 100 lt. de Enrofloxasina, cuyo valor CIF asciende a US $\$ 14330$ y para retirar la mercancía del terminal marítimo se requiere liquidar y cancelar los impuestos respectivos. ¿Cuáles son estos impuestos y a cuánto ascienden, considerando que en la fecha en que se cancelan, el TCV es S/. 3.20 por US \$?

\section{CALCULO:}

Valor de compra CIF

Impuesto Ad-Valorem, según arancel: 12\% x US\$ 14330

(+) IGV: $16 \%$ x US\$16049.60

(+) IPM: $2 \% \times \quad 16049.60$
US\$ 14330.00

1719.60
16049.60

2567.94

320.99

18938.53

Luego, los impuestos a pagar convertidos a moneda nacional, ascienden a:

\section{IMPUESTO}

Impuesto Ad-Valorem

IGV : $16 \%$

IPM : $2 \%$

\section{MEUS \$}

1719.60

2567.94

$\frac{320.99}{4608.53}$

ニニニニニニ
TCV

3.20

3.20

3.20
5502.72

8217.41

$\frac{1027.17}{14747.30}$
MN

$=======$ 


\section{CÁLCULO DEL COSTO DE IMPORTACIÓN}

El costo de las mercancías importadas está constituido por la suma facturada por el proveedor extranjero, según condición de compra previamente pactada (FOB, CIF, C\&F, etc.), más otros gastos incurridos para poner el producto en el almacén de la empresa, como: flete, seguro, gastos de despacho, derechos e impuestos de importación, transporte interno, acarreo, gastos de aduana, costo del servicio del banco local y corresponsal, entre otros. Se excluyen los impuestos que tienen la condición de crédito tributario, y los gastos de intereses por financiación de la compra, de haberlos.

Es necesario controlar minuciosamente los gastos y desembolsos que origina la importación de la mercancía, para lo cual se prepara instrucciones escritas sobre políticas de costeo y prácticas de registro a utilizar, y gastos que forman parte del costo de adquisición (gastos activables), siendo susceptible que algunos gastos considerados "menores" no formen parte del costo de adquisición, por lo que al recepcionar estos documentos se contabilizan aplicando cuentas de gastos y no la cuenta de control de activo. Esta política de costeo se sustenta en un sentido práctico de "costear" al activo únicamente sumas de relativa importancia, lo que está de acuerdo al PCGA de "Importancia relativa" o "Significatividad".

La importación de bienes afecta a los procedimientos regulares de registro, y es usual que se genere el pago de la obligación, pero no la recepción de la mercancía, sino en fecha posterior. Asimismo, será necesario crear libros o formatos especiales que se utilicen simultáneamente con los registros convencionales, lo cual depende de la frecuencia o regularidad con que la empresa efectúe importaciones.
Si la empresa efectúa frecuente importaciones de bienes, es necesario utilizar el formato preimpreso (adjunto): Control del Costo de importación, que equivale a una cuenta analítica del mayor (28 Existencias por recibir o 338 unidades por recibir), utilizada para centralizar y controlar los costos de importación, hasta transferir el costo acumulado a su cuenta definitiva a la recepción de la mercancía por el almacén del importador. Por cada artículo o lote importado se prepara un "file" adjuntado el formato de Control de Costo de Importación, en el cual simultáneamente al registro de los documentos en el libro contable correspondiente, se anota y archiva copia de los documentos sustentatorios.

La primera parte del formato Control del Costo de Importación contiene todos los datos referidos al origen (interno) del pedido, identificación del bien y proveedor, bancos participantes en la operación, medio de transporte, agente de aduana, fecha y condiciones de recepción del bien, etc. La segunda parte del formato contiene referencias monetarias, clasificado en función de la naturaleza del gasto o pago, convertido la ME a la moneda de curso legal del país. Las sumas registradas en cada línea equivale a la cuenta de control utilizada para registrar los costos, hasta el momento en que la suma acumulada se transfiera a la cuenta de control definitiva.

Si con posterioridad a la fecha de liquidación final del costo de importación, se recibiera documentos por desembolsos atribuibles al costo, estos se anotarán en el rubro de "Observaciones" y codificado a la cuenta de control definitiva que corresponda. Si hubieran desembolsos generados por la importación que por su cuantía o naturaleza (gastos por intereses, IGV, etc.) no son atribuibles al costo de adquisición, entonces se anota en el rubro de "Gastos no costea- 
bles", a efectos de evaluar la incidencia financiera de éstos.

El almacenero, al recepcionar la mercancía, emite el documento de control interno: Guía de Recepción o documento equivalente, en el cual se indica nombre del proveedor, características del bien, cantidad y condiciones de recepción, etc. El documento original es recepcionado por el área de contabilidad, quien procede a valorizar tomando el valor acumulado del formato Control del Costo de Importación, y contabiliza la mercancía a su cuenta definitiva. Por ejemplo, cargo a la cuenta 24 Materias primas y auxiliares, y abono a la cuenta 28 Existencias por recibir. Si hubieran unidades faltantes o cualquier anomalía, será comunicado al proveedor y al agente de seguro para gestionar la compensación de la pérdida o daño.

\section{DIFERENCIA DECAMBIO. INCIDENCIA EN EL COSTO DE'IMPORTACIÓN}

Las operaciones de importación necesariamente han de originar documentos expresados en ME (moneda extranjera), los que deben ser registrados en la moneda de curso legal del país. Para convertirlos en $\mathrm{MN}$ (moneda nacional), se aplica una tasa de cambio (tipo de cambio), pero como existen dos tasas, una aplicable a la compra de ME y otra a la venta, es necesario conocer la regla básica siguiente:

"Los activos en ME se valorizan a MN al TCC (tipo de cambio compra). Para expresar los pasivos en ME a MN, se utiliza el TCV (tipo de cambio venta) vigente a la fecha de registro o fecha de cierre del balance general".

Los documentos de la transacción de compra en $\mathrm{ME}$ se registran en $\mathrm{MN}$ y se aplica el TCV respectivo, lo que es susceptible de variar en el tiempo, por lo que el documento en ME dejará de ser su equivalente exacto de la $\mathrm{MN}$ al momento del pago o registro definitivo, generándose una ganancia o pérdida de cambio. Por ejemplo:

Como parte del costo de importación de una materia prima, el $02-11$ se ha registrado la F/. No 40899 por US \$2 124

\section{RESPUESTA:}

PROVEEDORES

42-1 Facturas por pagar

60

COMPRAS

60.9 Gastos vino, con las compras

10

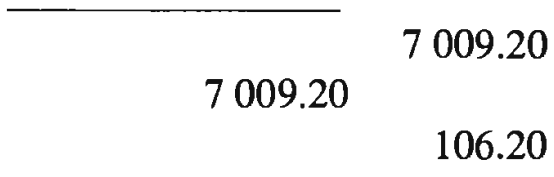

106.20

7115.40
10-41 Cuentas corrientes- B. Latino

7115.40

29-11.Pago de la Factura № 40899 o/. Seguros

El Cóndor S.A. por US \$2 124 a S/. 3.35
28 EXISTENCIASPOR RECIBIR

79 a CARGAS IMPUTABLES A CUENTAS DE COSTOS
106.20

106.20

Destino de la pérdida por diferencia de cambio. 
de Seguros El Cóndor S.A.A. al TCV de S/.3.30, luego la obligación en $\mathrm{MN}$ es S/.7009.20. El día 29-11 se paga la factura con cheque $\mathrm{N}^{\circ} 0891$ a cargo del Banco Latino por US $\$ 2124$, siendo el TCV de la fecha S/.3.35, luego la suma equivalente en MN es S/. 7115.40 ¿Cómo se contabiliza el pago?

Si la mercancía importada formara parte de las existencias en los almacenes de la empresa, la pérdida por diferencia de cambio se contabiliza en la cuenta de existencias; pero si parte de ella se hubiera vendido o consumido, se prorratea la diferencia de cambio, contabilizándose una parte en la cuenta 67 Cargas financieras, divisionaria 67-6 Pérdida por diferencia de cambio, y el saldo en la cuenta de existencias respectiva.

Si al cierre contable de cada mes y en particular del periodo, hubiera en el balance general saldos en la cuenta 28 Existencias por recibir y 33-8 Unidades por recibir, cuya contracuenta de pasivo estuviera pendiente de pago, se procede a actualizar el saldo en MN empleando el TCV que rige a la fecha de cierre del balance, la nueva suma se compara con la $\mathrm{MN}$ originalmente registrada y la diferencia ha de incrementar o disminuir el saldo de la cuenta 28 ó 33-8. En caso se hubiera ya recibido el bien, se efectúa el asiento contable de diario con cargo a la cuenta definitiva de existencia o activo fijo y abono a la cuenta 42 Proveedores.

Lo expresado es coincidente con lo establecido en la Ley Impuesto a la Renta (D.L.774), aplicable a las diferencias de cambio a que se refiere el capítulo $X$ del Régimen para Determinar la Renta, artículo 61 , y con el NIC 21. Tratamiento Contable de los Efectos de las Variaciones en los Tipos de Cambio de Moneda Extranjera.

\section{CONTABILIZACIÓN Y CONTROL DE LAS IMPORTACIONES}

En el lapso que media entre el acuerdo de compra-venta, recepción y pago de las mercancías importadas, se genera documentos que no son recepcionados en orden cronológico, por consiguiente habrá "desorden" en su registro, es usual registrar primero gastos secundarios o colaterales. Por ejemplo: (Comisión bancaria por apertura de carta de crédito) y no los documentos principales como factura del proveedor, transporte y seguro. Asimismo, se registra documentos por bienes importados pendientes de recibir por la empresa, por lo que transitoriamente se emplea cuentas provisionales de control del costo de adquisición, hasta que los bienes sean recepcionados. Previamente se tiene que haber determinado qué clase de gastos son "activables" o asumidos a resultados del periodo.

En el Perú, aplicando el PCGR, las cuentas de control previstas para el registro y acumulación preliminar del costo de importación, depende si se trata de existencias o activos fijos; así tenemos:

-Existencias.-. Incluye los bienes de propiedad de la empresa destinados a la venta en el estado original de adquisición (comercio) o a ser utilizados en los procesos de producción de bienes (industria) para la venta, y las destinadas a ser usadas o consumidas por la empresa. Las cuentas de existencias empleadas en los costos de importación están constituidas por 20 Mercaderías, 24 Materias primas y auxiliares, 25 Envases y embalajes, 26 Suministros diversos y 28 Existencias por recibir.

La cuenta 28 Existencias por recibir se emplea como cuenta de control preliminar de cualquiera de las cuentas antes señaladas, por los bienes pendientes de recepción. 
Recibido la mercancía se efectúa el asiento contable de diario, reclasificando la cuenta de control; esto es, se carga a la cuenta de control final a que se refiere la naturaleza del bien. Por ejemplo: (24 Materias primas y auxiliares) y se abona a la cuenta 28 Existencias por recibir. La suma acumulada se obtiene del formato Control del Costo de Importación o papel de trabajo respectivo.

-Activos fijos.- Incluye las cuentas representativas de los bienes de uso permanente al servicio de la empresa, y que disponen de una vida útil mayor a un año y no destinados a la venta. Las cuentas de activo fijo empleado en los costos de importación son: 33-3 Maquinaria, equipos y otras unidades de explotación, 33-4 Unidades de transporte, 33-6 Equipos diversos, 33-7 Unidades de reemplazo y 33-8 Unidades por recibir.

La cuenta divisionaria 33-8 Unidades por recibir es la que se emplea para centralizar en el transcurso del tiempo los costos atribuibles al bien importado aún no recibido por la empresa. A la recepción se transfiere con un asiento contable de diario el costo acumulado a la cuenta divisionaria definitiva que le sea aplicable según la naturaleza del activo fijo.

Las facturas y documentos afines en ME por obligaciones con proveedores de bienes y servicios se valorizan al TCV vigente a la fecha de registro o fecha indicada en el documento.Normalmente se aplica el TCV que corresponde a la fecha de emisión del documento, pero como éste se recibe generalmente con atraso de días, semanas y hasta meses, se puede utilizar el TCV que corresponde al día de registro del documento, siempre que no tenga implicancia con el crédito tributario por el IGV e ISC; por ejemplo, una nota de débito cargada en cuenta bancaria por comisión de apertura de crédito docu- mentario, se puede contabilizar con el TCV del día de su recepción.

Entre los documentos recepcionados por el área de contabilidad, algunos se encuentran pendientes de pago y otros están pagados. Esta condición modifica el tratamiento contable; así tenemos:

a) Documentos pagados.- Si la factura o documento afín está expresado en ME, pero se ha pagado por su equivalente en $M N$, no se efectúa conversión alguna, salvo la verificación de el TCV que debe corresponder a la fecha de pago, y se procede a cargar a la cuenta de cargas por naturaleza 60 Compras y destino 28 Existencias por recibir o a 42 Proveedores (por la obligación cancelada), y se abona a la cuenta 10 Caja y bancos.

En cambio, si la factura está emitida en ME y se ha pagado con $\mathbf{M E}$, entonces la suma se convierte a $\mathrm{MN}$ aplicando el TCV que corresponde al día del pago, teniendo cuidado que si se trata de obligaciones previamente provisionadas en $\mathrm{MN}$, se carga a la cuenta de pasivo por la suma ya registrada en $M N$, y no la que es producto de la aplicación de la cotización de la ME al día del pago. La diferencia de cambio se afecta a la cuenta de control preliminar de la mercancía y si ésta se encuentra en el almacén, se carga a su cuenta de control definitiva. Por ejemplo: (24 Materias primas).

b) Documentos por pagar.- Si la factura o documento afín está expresado en MN y, por consiguiente, el pago ha de realizarse en la misma moneda, entonces el tratamiento contable consiste en cargar a la cuenta 60 Compras y por destino a 28 Existencias por recibir, y acreditar a 42 proveedores. Si el documento a pagar está expresado en ME, para su registro se requiere conocer el TCV que corresponde a la fecha de emisión 
del documento, pudiéndose optar por utilizar el TCV del día en que se efectúa el registro contable o del último día del mes, a condición que el documento no incluya créditos tributarios por IGV o ISC. El TCV se multiplica por la ME, la suma obtenida es el equivalente en $\mathrm{MN}$ a desembolsar en el futuro.

No debe el lector olvidar que las facturas del proveedor extranjero y del agente de aduana, entre otros, debe ser anotado en el Registro de Compras por su equivalente en $\mathrm{MN}$, y simultáneamente las sumas que constituyen parte del costo de importación se registra en el formato: Control del Costo de Importación, de esta hoja se traslada la suma acumulada a la cuenta definitiva de control, al recibir el almacén la mercancía importada.

Un caso especial son las facturas que no incluyen IGV emitidas por las empresas supervisoras de importaciones contratadas en el país para emitir el Certificado de Inspección, cuya labor es realizada en el exterior, por lo que las sumas abonadas no califican como renta de fuente peruana y, por consiguiente, no están afectos al Impuesto a la Renta y por extensión al IGV a cargo del emisor; pero el usuario sí se encuentra gravado con el IGV, porque los servicios prestados por no domiciliados fuera del territorio nacional son utilizados en el país. De acuerdo al literal b) del artículo 1 de la Ley del IGV e ISC, la empresa usuaria debe pagar el IGV.

El pago del IGV podría efectuarse al emitir comprobante de pago; sin embargo, se debe proceder a declarar y pagar el IGV empleando el formulario de la SUNAT 182 para medianos y pequeños contribuyentes o 282 para principales contribuyentes. Ambos formatos se emplean como "Declaración Pago de Retenciones de IGV por Liquidaciones de Compra y Pago de Utilización en el país de Servicios Prestados por no Domiciliados". El IGV generado en esta operación, una vez pagado y anotado en el Registro de Compras, tiene la condición de crédito tributario, de acuerdo a lo dispuesto en el literal c) del artículo 19 de la Ley del IGV e ISC (D.L. 821).

Se reitera que los documentos a pagar referidos a la importación de la mercancía, que por su naturaleza no forman parte del costo de importación, como es el caso del crédito tributario por IGV e ISC, así como los gastos menores o financieros, se debita a las subcuentas 40-11 Impuesto General a las Ventas, 40-12 Impuesto Selectivo al Consumo, 67 Cargas financieras, y en general la que corresponda al caso.

\section{BIBLIOGRAFÍA}

Decreto Legislativo No 809 del 19-04-96Ley General de Aduanas.

Decreto Supremo $N^{\circ}$ 121-96-EF publicado el 24-13-96. Reglamento de la Ley General de Aduanas.

Decreto Legislativo $\mathrm{N}^{\circ}$ 821. Texto Único Ordenado de la Ley del IGV e ISC, promulgado por D.S. $\mathrm{N}^{\circ}$ 055-99-EF, publicado el 15-04-99.

Resolución de Superintendencia N ${ }^{\circ}$ 007-99/ SUNAT publicado el 24-01-99. Reglamento de Comprobantes de Pago.

Decreto Legislativo $N^{\circ} 774$. Texto Único Ordenado de la Ley del Impuesto a la Renta, aprobado por D.S. $\mathrm{N}^{\circ}$ 054-99-EF, publi cado el 14-04-99.

Revista: Informativo Caballero Bustamante. Artículos varios. 